\title{
A Psychological Profile of Acculturation, Ethnic Identity and Teaching Efficacy among Latino In-service Teachers
}

\author{
Fuhui Tong (Corresponding author) \\ Department of Educational Psychology, Texas A\&M University \\ College Station, TX 77843, U.S \\ Tel: 1-979-845-7979Ｅ-mail: fuhuitong@tamu.edu \\ Linda G. Castillo \\ Department of Educational Psychology, Texas A\&M University \\ College Station, TX 77843, U.S \\ Tel: 1-979-845-0891_E-mail: lcastillo@tamu.edu \\ Aida E. Pérez \\ Department of Educational Psychology, Texas A\&M University \\ College Station, TX 77843, U.S
}

Tel: 1-979-845-2599Ｅ-mail: aeperez@tamu.edu

\begin{abstract}
This study examined psychological constructs of acculturation, ethnic identity, and teaching efficacy among 89 Latino in-service teachers serving minority students. Results showed significant differences in these constructs in relation to certification, program taught, and years of teaching. First, bilingual teachers were less likely to be assimilated to White-American culture compared to traditionally/alternatively prepared ESL teachers. Second, traditionally certified ESL teachers were more efficacious in controlling disruptive behavior than alternatively prepared ESL teachers. Finally, higher acculturated teachers were associated with university route and ESL program while low acculturation individuals were more likely to hold alternative certification and teach in bilingual program. Educational implications were discussed.
\end{abstract}

Keywords: Acculturation, Ethnic identity, Teaching efficacy, Bilingual/ESL, Latino in-service teachers, Route to certification, Teacher characteristics

\section{Introduction}

The dramatic increase of English language learners (ELLs, or used interchangeably with the term of language minority students) in the U.S. public schools presents a challenge to prepare an effective and competent teacher force to accommodate the cultural, linguistic, and academic needs of these students (August \& Shanahan, 2006). This challenge becomes even more pressing with the push for educational reform, as reflected in No Child Left Behind (NCLB, 2002) mandating that each bilingual or English-as-Second-Language (ESL) classroom serving ELLs must be equipped with a highly qualified teacher, who is credentialed and holds a degree or significant expertise in the area $\mathrm{s} / \mathrm{he}$ teaches. However, studies revealed that a significant portion of teachers did not feel well trained for the complexities of teaching ELLs (Karabenick \& Clemens Noda, 2004), and were inclined to leave their profession (Friedman \& Farber, 1992; Monsivais, 1990). Such sense of incapability, according to Karabenick and Clemens Noda, results from limited knowledge of students' culture, as well as unfamiliarity with the role that first language plays during second language acquisition. Further, the ever-changing demographics of teachers nationwide have not paralleled those of the minority students. For example, according to the School and Staffing Survey (National Center for Education Statistics [NCES], 2008), in school year of 2003-2004, nearly $40 \%$ of the student population in elementary and secondary schools was composed of ethnic minorities with $17.7 \%$ identified as Latino, as compared to $16.9 \%$ of the public teacher force being minority with $6.2 \%$ Latino. The disparity between students' and teachers' ethnic background was evident. Consequently, researchers are concerned with this mismatch, which is likely to lead to teacher bias (Sheets, 1996), lack of ability to motivate students (Galguera, 1998), and cultural discontinuity between students' communities and schools (Ogbu, 1995). Perceivably, to increase the diversity of the teacher force and recruit teachers with shared ethnic and linguistic background of ELLs, to some extent, may remedy such problems, and thus, bring an advantage into the classroom (Flores, Strecker, \& Perez, 2002). Finally, a growing bilingual/English-as-second-language (ESL) staff vacancy underscores the importance of training veteran teachers to work effectively with new populations of 
ELL immigrants (NCES, 2008). Nevertheless, very few studies have elicited the voices of ELL teachers placed in English learning programs (i.e., bilingual or ESL); and even less has been ascertained among those teachers, who themselves are, ethnic minorities.

\subsection{Rationale of this Study}

Existing literature has provided evidence that teachers' belief in the ability to teach directly influences their instructional behavior, which in turn, promotes students' outcomes and success (de Mesquita \& Drake, 1994; Goddard, Tschannen-Moran, \& Hoy, 2001). It has also been reported that minority pre-service teachers' self-concept including ethnic identity positively affected their teaching efficacy (Flores \& Clark, 2004). Therefore, it is crucial to develop an understanding of the psychological constructs of teaching efficacy, acculturation and ethnic identity of minority teachers who are serving ELL students, and to examine differences in these aspects as a result of teaching experience, route to certification, and program taught. In this exploratory study, the following questions are to be addressed:

1) What is Latino in-service teachers' acculturation configuration, and are there differences by teaching experience, route to certification, and program taught?

2) What is Latino in-service teachers' ethnic identity configuration and are there differences by teaching experience, route to certification, and program taught?

3) What is Latino in-service teachers' sense of teaching efficacy, and do they differ by teaching experience, route to certification, and program taught?

4) What is the relationship between level of acculturation and ethnic identification with Latino in-service teachers' teaching experience, route to certification, and program taught?

\section{Theoretical Framework}

\subsection{Acculturation}

Scholars have noted that psychocultural factors such as acculturation and ethnic identity influence how teachers interact with students (Flores \& Clark, 2004). For Latinos teachers who are often the first in their family to go to college, acculturation and ethnic identity issues are often challenged during their college years (Castillo et al., 2006a; Castillo, Conoley, \& Brossart, 2004). Latinos who desire to enter the teaching profession must succeed in schools and college. However, in order to be successful, they must go through an acculturation process in which they acquire language, behaviors, and values associated with school culture (Castillo, et al., 2006a, Wren, 1999).

Acculturation is a process of cultural and psychological changes that follows intercultural contact (Berry, 2003). Acculturation involves two major processes: (a) adapting to the norms of dominant group culture and (b) maintenance of heritage culture group norms. Because the U.S. educational system and schools reflect White American values and beliefs (Castillo et al., 2004; Flores, Ojeda, Huang, Gee, \& Lee, 2006), a Latino college student is dealing with two different cultural groups: Latino and the school culture (Castillo et al., 2004). School culture has been defined as the social and cultural conditions, which include practices, policies, and behaviors that constitute the working and learning environment (Castillo et al., 2006b). For many predominately White schools in the U.S., the school culture is composed of the values, beliefs, and behaviors of White American culture (Castillo et al., 2006b; Wren, 1999).

Aguilar, MacGillivray, and Walker (2009) described the acculturation process that many Latino teachers experienced. They purported that Latina teachers engaged in a process of incorporating and blending two types of discourse: school culture (which includes being a teacher) and home culture (i.e., heritage culture norms). Discourse is defined as "a socially acceptable way of using language that can identify oneself as a member of a social meaningful group" (p. 131). Aguilar et al. contended that for Latina teachers the successful acquisition of becoming a teacher required development and integration of a new identity (teacher identity) while at the same time maintaining their home culture. However, when values of school culture and home culture conflicted, painful tensions could result that can influence an individual's cultural identity. As noted in this qualitative study (Aguilar et al., 2009), many bilingual Latina teachers experienced a homogenization during their training where they were expected to "shed" their heritage cultural norms and become assimilated to White American culture in order to be successful. However, as noted by the participants in the study, they were assumed and expected to "instinctively teach in culturally appropriate ways" once they began teaching (p. 99). This conflict between the school discourse where the expectation is to assimilate to White American culture can potentially conflict with the development and maintenance of ethnic identity to one's heritage culture.

To explore the complexity of the acculturation process within the Latino groups, Flores, Clark, Guerra, and 
Sánchez (2008) compared three groups of prospective bilingual teachers, i.e., first-generation college students seeking an initial degree with bilingual education certification; paraprofessionals who were part-time college students seeking an initial degree with bilingual education teaching certification; and normalistas (foreign-trained teachers with certification from Mexico) seeking bilingual education teaching certification. It was found that acculturation process was dependent upon age and generation because the first-generation group demonstrated greater disagreement with Mexican family values and acculturative shift to the mainstream society. The authors recommended that teacher preparation program attended to acculturation issues of Latino teacher candidates so as to help them better understand themselves and their prospective students.

\subsection{Ethnic Identity}

Acculturation theorists have noted that the acculturation process can also elicit changes in the affective level of functioning also known as ethnic identity (Cuellar, Arnold, \& Maldonado, 1995). Ethnic identity is defined as one's self-identification as part of an ethnic group, or subgroup claiming common ancestry and sharing a variety of cultural elements (Phinney, 2003). As Latinos undergo an acculturation process during their college preparation program, the socialization into the teaching profession also has an influence on their ethnic identity (Flores \& Clark, 2004). Scholars have noted the importance of ethnic identity for teachers (Flores \& Clark, 2004; Flores, 2001; Villegas \& Lucas, 2002). For instance, Flores (2001) suggested that teacher candidates should have an ethnic consciousness and become connected with ethnic membership issues. This is particularly important as studies have shown ethnic identity to be related to self-efficacy (Flores \& Clark, 2004), self-esteem (Phinney, Chavira, \& Tate, 1993), self-concept and teacher identity (Clark \& Flores, 2001), and cultural competence (Castillo et al., 2006a).

Individuals with high ethnic identity are more likely to participate in their ethnic group's cultural practices and incorporate their culture's values and beliefs (Phinney, 1996). The development and maintenance of one's ethnic identity is important for teachers because studies have shown that teachers having a similar cultural framework as their students are more likely to be attuned to their students' needs (Peña, 1997). Furthermore, studies have shown that students are more likely to prefer teachers with similar cultural characteristics and ethnic match has been related to academic achievement (Galguera, 1998; Meier, Wrinkle, \& Polinard, 1999; Zirkel, 2002).

\subsection{Teaching Efficacy}

Since its inception, the psychological construct of teacher efficacy has been examined by a handful studies with the effort mainly devoted to mainstream White American in-service or pre-service teachers (Ashton \& Webb, 1986; Dellinger, Bobbett, Olivier \& Ellett, 2008; Gibson \& Dembo, 1984; Jerald, 2007; Tschannen-Moran \& Hoy, 2001). Teacher efficacy is defined as the belief that one has capabilities in the areas of student engagement, instructional strategies, and classroom management that can be used to bring about a desired outcome in student commitment and learning (Tschannen-Moran \& Woolfolk-Hoy, 2001). Many studies on teacher efficacy suggest that those who are more confident in their teaching tend to exhibit more positive (e.g., praising, smiling) and less negative (e.g., criticizing, punishing) behaviors while interacting with their students, adapt innovation and change (Ghaith \& Yaghi, 1997), and remain longer in their teaching profession (Ware \& Kitsantas, 2007). Consequently, students' academic success can never be separated from teacher effectiveness.

Unfortunately, research addressing issues of teaching efficacy have focused on mainstream populations, making the study of teaching efficacy among ESL and bilingual teachers very limited in number and scope. One of the few studies to examine teacher efficacy with bilingual teachers was conducted by Flores and Clark (2004) who sampled 44 foreign-born (normalistas) pre-service teachers on their teaching efficacy and self-concept. These pre-service teachers held foreign teaching certifications and participated in a traditional teacher preparation program in the United States. Results from the study revealed than on average these teachers possessed a positive sense of their ability in teaching. Yet, results also showed that approximately $20 \%$ of the sample believed that their students' success in school was determined by external factors beyond the teachers' control.

In a related vein, Flores (2001) explored in-service bilingual teachers' beliefs about the nature of knowledge and found that teachers with alternative certification had a sense of powerlessness to change the status quo within the school system and felt inadequately prepared to work with students. The author therefore underscored the importance of teacher preparation on teaching practice, and suggested that valid theory and practice should be bridged in professional teacher training.

Besides Flores' (2001) study, other researchers have also found that route to certification influenced teaching efficacy. For example, Flores, Desjean-Perrotta, and Steinmetz (2004) reported that teachers who went through a traditional route (i.e., university-based program) held higher sense of efficacy as compared to teachers with alternative certification. This finding was further confirmed by Tong (2009) who sampled 133 bilingual and ESL 
teachers in an urban school district and compared these teachers' efficacy by route to certification. Her study revealed comparatively low general teaching efficacy among alternatively certified teachers. These teachers were less confident in the notion that the limitations of students' family environment can be overcome by education in the school. In addition to route to certification, teacher's age, years of teaching, and program taught have also found to be related to teaching efficacy. For example, teachers at upper age level were more self-reliant and tended to easily overcome the obstacles of their students' education (Celep, 2000). Ghaith and Yaghi (1997) concluded that more experienced secondary teachers tended to believe that their ability to perform actions leading to student success is limited by factors beyond school control. Conversely, a survey conducted among 162 White American in-service teachers revealed that teachers with over three years of teaching experiences showed a higher level of confidence in their teaching competence (Flores et al., 2004). Finally, bilingual teachers were more likely to have strong belief in control of learning within their classroom than special education or reading teachers (Flores et al., 2004).

\section{Method}

\subsection{Participants}

This study derived from a larger project with a convenience sample of bilingual/ESL teachers in a large urban school district in southeast Texas where there was historically high concentration of ethnic minority students primarily with Latino background. In the 2007-2008 school year, $29.7 \%$ of the student body was identified as ELLs, and a majority of students (79.5\%) qualified for free or reduced lunch. Both of the numbers are higher than that of the state level. Approximately $28 \%$ of the students in this district were placed in bilingual/ESL programs with 245 teachers (TEA, 2008). The survey was distributed at the district's bilingual/ESL teacher conference during the spring 2008. Participation was completely voluntary and anonymous. Neither the names of the teachers nor the schools were included in any part of the survey. For the purpose of this study, only those who identified themselves as Latino were included in the final sample, totaling 89 teachers, with 63 female and 25 male. One respondent did not provide his/her gender. Sixty-five percent $(n=58)$ of the participants reported Spanish as their native language, $12 \%(\mathrm{n}=11)$ reported English as their native language, and $21 \%(\mathrm{n}=19)$ reported being bilinguals in English and Spanish. One respondent did not provide her native language. Ninety-three percent $(n=83)$ of the participants reported being elementary school teachers teaching up to six grade. In addition, $44 \%(\mathrm{n}=39)$ of the respondents received their certification at an institution of higher education with $16.8 \%$ of them reporting advance/ graduate level degrees. Fifty-four percent $(n=48)$ received their certification through alternative programs. One participant did not provide her route for certification. Sixteen percent $(n=14)$ of the sample reported between 1 to less than 5 years of teaching experience, $39 \%(n=35)$ reported between 5 to 10 years of experience, $35 \%(n=31)$ reported between 11 to 20 years of experiences, and $8 \%(\mathrm{n}=7)$ had over 21 years of experience. Two respondents did not report their number of years of experience. Thirteen percent of teachers $(n=12)$ held ESL certification and $85 \%(n=76)$ held bilingual certification. Details are provided in Table 1 with the breakdowns of demographic background by programs served, years of experience, route to certification, and degrees held.

\subsection{Survey Instrument}

The survey for this study contains three scales as well as three demographic questions. The three scales measured Latino teachers' sense of teaching efficacy, ethnic identity, and acculturation. The demographic items asked for years of teaching, program taught, and route to certification.

\subsubsection{Acculturation}

Acculturation was assessed using the Acculturation Rating Scale for Mexican Americans II (ARSMA-II; Cuéllar, Arnold \& Maldonado, 1995). Although originally created for Mexican American adults, the ARSMA II has been validated and used widely in studies of Latino adults. The ARSMA-II contains a Mexican (Latino) Orientation score and an Anglo (White American) Orientation score which are reported to have internal reliability with Chronbach's alphas of .86 and .88, respectively (Cuéllar et al., 1995). Scores of the subscales are calculated by summing the responses within each subscale and dividing by the number of items. Higher scores indicate high levels of acculturation. In addition, scores can be used to classify participants into five types of acculturation, namely, 'Very Mexican/Latino Oriented', 'Mexican/Latino Oriented to approximately balanced bicultural', 'Slightly Anglo/White American oriented bicultural', 'Strongly Anglo/White American oriented', and 'Very assimilated, Anglicized'. The internal consistency of the current sample had a Cronbach's alpha of .85.

\subsubsection{Ethnic Identity}

Ethnic identity was assessed using the Multigroup Ethnic Identity Measure - Revised (MEIM-R; Phinney \& Ong, 
2007). The MEIM-R is a shorter version of the original MEIM (Phinney, 1992). A series of exploratory and confirmatory factor analyses converged to two independent dimensions of ethnic identity- commitment and exploration, with Chronbach's alphas of .76 and .78 , respectively. Both dimensions can be assessed separately as well as a single measure, and the internal consistency of the entire scale was reported to have a Cronbach's alpha of .81 . The commitment dimension of the MEIM-R was conceptualized as a sense of belonging, whereas the exploration dimension was presented as an individual's active seeking of activities that are relevant to his/her ethnic group. Response to each of the six items is along a five-point Likert scale, from 1 for "strongly disagree" to 5 for "strongly agree". Scores are calculated for each dimension by averaging the items within that dimension. In addition, a total score is calculated with the average of all items for the subsequent analysis (with a possible maximum of 5). The internal consistency of the current sample had a Cronbach's alpha of .94.

\subsubsection{Teaching Efficacy}

The dimensions of efficacy were assessed using a version of the long form of the Ohio State Teacher Efficacy Scale (OSTES; Tschannen-Moran \& Hoy, 2001). During the development of the OSTES, a series of factor analyses revealed three factors for in-service teachers. These were efficacy for instructional strategies, efficacy for classroom management and efficacy for student engagement. Response to each item is along a nine-point Likert scale, from 1 for "Nothing" to 9 for "A great deal". For all three dimensions, a higher score corresponds to higher efficacy for a teacher. In assessing the scale's construct validity, the OSTES developers correlated it with other measures of teaching efficacy such as the Teacher Efficacy Scale (Hoy \& Woolfolk, 1993) and reported that the OSTES and alternate measures were positively correlated, suggesting reasonable validity and reliability. Internal consistency of the current sample had a Cronbach's alpha of .93. Dependent variable was calculated as the average of items within each factor, and of all items, with a possible maximum of 9 .

\subsection{Data Analysis}

To answer first three questions, three-way (i.e., years of teaching, route to certification, and program taught) univariate analysis (with teaching efficacy, acculturation and ethnic identity being dependent variables respectively) will be used and interaction term among the three factors will be included as well. In case when significant result is present, effect size will also be reported as symbolized by partial eta square. To address the last question, correlational analysis will be conducted.

\section{Results}

\subsection{Acculturation}

The average acculturation score of the current sample was -.135 with a standard deviation of .684 . The three-way univariate analysis yielded significant main effect of program, $F(1,82)=9.890, p=.002$, partial eta square $=.122$, suggesting that bilingual and ESL teachers differed in the acculturation score. An examination of the results found that ESL teachers obtained a higher estimated marginal mean $(M=.501)$ than did the bilingual teachers $(M=-.227)$. Such difference was further reflected by a significant interaction effect between route and program, $F(1,82)=5.153, p=.026$, partial eta square $=.068$, suggesting that ESL teachers who were alternatively-certified had the highest estimated marginal mean $(M=1.335, S E=.449)$, followed by ESL teachers who were traditionally-certified $(M=.292, S E=.263)$, as compared to bilingual teachers who were alternatively-certified $(M=-.371, S E=.101)$ (see Figure 1).

\subsection{Ethnic Identity}

The average total score of ethnic identity scale of the entire sample was $3.87(S D=1.03)$. There were six cases that scored two $S D$ s below the mean. A significant main effect of program was revealed, $F(1,78)=4.031, p$ $=.049,=\eta_{p}{ }^{2}$ 057, with ESL teachers having a higher marginal mean $(M=4.62, S E=.37)$ than bilingual teachers $(M=3.68, S E=.14)$. In addition to the main effect, a significant interaction effect between route and years of teaching, $F(2,78)=3.144, p=.031$, partial eta square $=.098$, suggesting a higher marginal mean score for traditionally-trained teachers with $11-20$ years of teaching $(M=4.51, S E=.39)$ than those alternatively-trained teachers $(M=3.58, S E=.26)$ with same amount of teaching experience (see Figure 2). When analyses were conducted on individual factors, results followed similar pattern with significant main and interaction effects obtained in exploration, $F \mathrm{~s}>3.01, \quad p \mathrm{~s}<.05$, partial eta squares $>.07$; and significant interaction effect obtained in commitment, $F=3.93, \quad p=.02$, partial eta square $=.10$.

\subsection{Teaching Efficacy}

The average composite efficacy score of the entire sample was $8.163(S D=.708)$. Three-way univariate analysis did not yield significant main, with a marginally significant interaction effect between program and route, $F$ ( 2 , $80)=3.759, p=.059$, partial eta square $=.062$. When the three factors were analyzed separately, same results 
were obtained for efficacy in classroom management in which interaction effect of route and program was detected, $F(2,80)=6.534, p=.013$, partial eta square $=.104$. In addition, significant main effect of route was also evident, $F(1,80)=4.744, p=.034$, partial eta square $=.078$, suggesting that traditionally-prepared ESL teachers had a higher marginal mean score $(M=8.59, S E=.31)$ than alternatively-prepared ESL teachers $(M=$ 7.5, $S E=.59)($ see Figure 3).

\subsection{Relationships among Level of Acculturation, Ethnic Identity, Route to Certification, Years of Teaching, And Program Taught}

To understand the nature of the relationships of the study variables, participants were divided into high and low acculturation and ethnic identity levels. For the acculturation variable, high-low groups were calculated by using the cutoff score of -.07 with scores greater than -.07 classified as the high acculturation group and lower scores in the low acculturation group (Cuéllar et al., 1995). For the ethnic identity variable, high-low groups were calculated by using the cutoff score of 3 with greater scores being classified to the high ethnic identity group and lower scores in the low ethnic identity group (Phinney \& Ong, 2007). The correlational analysis yielded a statistically significant relationship between level of acculturation and (a) program, $r=-.354, p=.001$, and (b) route, $r=-.211, p=.05$. No significant relationship was identified between level of ethnic identity and program or route. Finally, program and route to certification were found to be significantly correlated with each other, $r$ $=.241, p=.026$.

\section{Discussion}

The average acculturation level of Latino teachers in this study was "Mexican oriented to approximately balanced bicultural." It is important, and probably beneficial, for ethnic minorities to develop a bicultural perspective so as not to be isolated from either the minority or the majority group (Bautista de Domanico, Crawford, \& de Wolfe, 1994). However, acculturation levels differed by the type of program the participants taught (ESL or bilingual) and route to certification. Results indicated that the acculturation level was "strongly Anglo oriented" for alternatively-certified ESL teachers, "slightly Anglo oriented bicultural" for traditionally-certified ESL teachers, and "Mexican oriented to approximately balanced bicultural" for bilingual teachers. This classification highlighted an interesting finding that although all teachers participating in this study were Latino, their acculturation levels varied as a result of program type and route to certification. Teachers in programs where native language is part of the curriculum (i.e., bilingual programs) were less acculturated to the White American culture and more retained to their heritage culture. In contrast, teachers in programs where English is the sole language of instruction (i.e., ESL) were more likely to be assimilated to White American culture, especially when they went through an alternative certification program. It is possible that ESL programs, which focus on assimilation to the English language (Genesee, 1999; Menken, 2008), attract individuals who are more acculturated. Since bilingual programs emphasize both adoption of English and retention of the heritage culture language (Cummins, 2000), participants who are desire to retain their heritage culture may be more attracted to bilingual programs rather than ESL programs. Furthermore, in bilingual programs, teacher candidates are usually expected to respect their language minority students' culture (Cabello \& Burstein, 1995), function successfully in cross-cultural setting (Giles, Coupland, Williams, \& Leets, 1991), and understand the relationship between culture and language (Chisholm, 1994) so as to provide quality education to ELLs.

The majority of the teacher participants in our study held a moderate level of ethnic identity; however, some exhibited a minimal interest in exploring their own ethnicity and community, and a lack of sense of belonging. Such finding is not surprising because ethnic identity is proposed to be negatively associated with the need for survival in new/mainstream sociopolitical context (i.e., U.S. in this current study) (Trueba, 2002). Therefore, recent immigrants do not experience internal conflict to maintain their ethnic identity while learning a new culture and a new language; and have been reported to have a closely-rooted Mexican identity among pre-service bilingual teachers (Flores \& Clark, 2004). In Flores and Clark's study, for example, Mexican teachers were assessed how they identified themselves ethnically before entering a bilingual teacher preparation program in the U.S. These teachers did not struggle in the notion of ethnic identity because "they come from a country where their identity is continually affirmed" (p. 242). Flores and Clark further suggested that these foreign-trained teachers had not developed sociopolitical awareness of what it means to identify ethnically. On the contrary, nearly $86 \%$ of the teachers in our study had at least 6 years of teaching in the U.S, in addition to the amount of time it took for them to be fully certified; therefore, they cannot be considered recent immigrants, which may explain their lack of sense of belonging. An interesting finding is that although ESL teachers were more acculturated, they had higher ethnic identity score than bilingual teachers. This is contrary to previous research that has found acculturation to be negatively correlated to ethnic identity (Cuéllar, Nyberg, Maldonado, \& 
Roberts, 1998). A possible explanation is that nearly $70 \%$ of ESL teachers in our study tended to choose the university route for certification. Conceivably, these universities certification programs may have more opportunities for individuals to participate and develop ethnic identity (e.g., Latino student organizations), which also help explain our finding that as Latino teachers stayed longer in their profession, their sense of ethnic-self increased among traditionally certified teachers, while decreasing among alternatively certified teachers.

Using the Teachers' Sense of Efficacy Scale, we were able to capture what Tschannen-Moran and Woolfolk-Hoy (2001) termed as "an elusive construct" of teaching efficacy. In general, teachers in this study demonstrated a strong sense of efficacy and they believed in their capacities of dealing with disruptive behaviors, implementing a variety of strategies and motivating the least-interested students. Similar to other studies with pre-service or in-service teachers (Flores, Desjean-Perrotta, \& Steinmetz, 2004; Tong, 2009), our study revealed that traditionally-prepared teachers held a higher level of confidence in teaching as compared to alternatively-prepared teachers. Such difference was more evident among ESL teachers. Specifically, in our study, ESL teachers with a traditional route to certification were more efficacious in their ability to control disruptive behavior. Students' disruptive behaviors have implications beyond the learning environment; they can inhibit how and what teachers feel they can teach. Researchers have agreed that classroom management is one among those critical elements that influence school learning (Marzano, Marzano, \& Pickering, 2003; Wang, Haertel, \& Walberg, 1993; Wayman, Foster, Mantle-Bromley, \& Wilson, 2003), and should be incorporated into teacher preparation programs. Therefore, the finding of this study implies a strong likelihood that traditional teacher preparation programs stress on the importance, as well as the skills of dealing with disruption during instruction.

Further, the finding of this study is contrary to studies involving mainstream samples (Houston, Marshall, \& McDavid, 1993; Tournaki, Lyublinskaya, \& Carolan, 2009) that there was no difference between traditionally-prepared and alternatively-certified teachers regarding their confidence level of teaching. These mixed findings on teacher efficacy might result from (a) the operational definition, and therefore, the related variety of instruments implemented in each study, measuring general and personal teaching efficacy (e.g., Flores et al., 2004, Tournaki et al.. 2009), content-specific efficacy in instruction, management and involvement (e.g., the current study), or perceived problems by open-ended questionnaire (e.g., Houston et al., 1993); and (b) the ethnicity of teacher participants; for example, in Flores et al.'s (2004) and current study, participants were mostly ethnic minorities while in Houston et al. and Tournaki et al. participants were Whites. Hence, the question as whether teachers from traditional and alternative preparation programs differ in their efficacy deserves future research with other ethnic groups using reliable and valid instruments.

Finally, the correlational analysis confirmed the findings derived from research question one in that bilingual teachers and teachers with alternative certification were less assimilated to the Anglo culture as compared to ESL teachers and teachers with traditional certification. In addition, the fact that higher acculturated individuals were associated with a university certification and an ESL program while low acculturation individuals were more likely to hold an alternative certification and teach in a bilingual program brings information on the type of characteristics that attract individuals to certain routes and programs for recruitment.

\section{Conclusions and Implications}

This study has several implications for practice. First, it calls for thoroughly-designed efficacy-building professional development for in-service teachers to maintain, and more importantly, enhance the level of belief in one's capabilities in teaching ELLs regardless of their background, because as Goddard, Hoy, and Hoy (2000) reminded us, "It is not enough to hire and retain the brightest teachers - they must also believe they can successfully meet the challenges of the task at hand" (p. 503).

Second, this study provides a psychological profile of Latino teachers' acculturation configuration and their ethnic identification. The fact that higher acculturated individuals tend to take a university route and ESL program while low acculturation individuals who take more of an alternative route and a bilingual program presents educators and administrators with valuable information on the type of characteristics that attract individuals to certain routes and programs. It is also important to implement research-based quality teacher training programs embedded within a social-cultural framework for Latino teachers, or minority teachers in general, to feel proud of who they are, to embrace the mainstream culture, and to maintain their own identity, which can be then translated into a role model for their minority students.

It is also worth noting that the psychological constructs examined in this study are dynamic process in continual change. For example, we did not know whether these teachers' acculturation level influenced their choice of certification route and/or type, or whether their acculturation increased or decreased as a result of certification route and/or type. Therefore, future studies are highly needed to address the change, with preferably a pre-post 
design, and to identify factors that cause such change.

In conclusion, in Latino culture, there is a prevalence of teacher authority (Espinosa, 1995). Taking this into consideration, it is critical to represent a more comprehensive psychological profile of teachers working with Latino ELLs. This study, to some degree, provides a step toward a better understanding of this profile so as to facilitate future research exploring causal effect of teacher quality and students' learning outcome.

\section{References}

Aguilar, J. A., MacGillivray, L. \& Walker, N. T. (2009) Latina educators and school discourse: Dealing with tension on the path to success. Journal of Latinos and Education, 2(2), 89-100.

August, D. \& Shanahan, T. (2006). Developing literacy in second-language learners. Report of the national literacy panel on language-minority children and youth. Mahwah, NJ: Lawrence Erlbaum Associates, Publishers.

Ashton, P. T. \& Webb, R. B. (1986). Making a difference: Teacher's sense of self-efficacy and student achievement. New York: Longman.

Bautista de Domanico, Y., Crawford, I. \& DeWolfe, A. (1994). Ethnic identity and self-concept in Mexican-American adolescents: Is bicultural identity related to stress or better adjustment? Child and Youth Care Forum, 23(3), 197-206.

Berry, J. W. (2003). Conceptual approaches to acculturation. In K.M. Chun, P.B. Organista, \& G. Marin (Eds.), Acculturation: Advances in theory, measurement, and applied research (pp. 17-38). Washington, DC: American Psychological Association.

Cabello, B. \& Burstein, N. D. (1995). Examining teachers' beliefs about teaching in culturally diverse classrooms. Journal of Teacher Education, 46 (4), 285-294.

Castillo, L. G., Conoley, C. W., \& Brossart, D. F. (2004). Acculturation, white marginalization, and family support as predictors of perceived distress in Mexican American female college students. Journal of Counseling Psychology, 51, 151-157.

Castillo, L. G., Conoley, C. W., Choi-Pearson, C., Archuleta, D. J., Van Landingham, A., \& Phoummarath, M. J. (2006a). University environment as a mediator of Latino ethnic identity and persistence attitudes. Journal of Counseling Psychology, 53, 267-271.

Castillo, L. G., Conoley, C. W., King, J., Rollins, D., Veve, M., \& Rivera, S. (2006b). Predictors of racial prejudice in White American counseling students. Journal of Multicultural Counseling and Development, 34, $15-26$.

Celep, C. (2002). The correlation of the factors: The prospective teacher's sense of efficacy, beliefs, and attitudes about student control. National Forum Journals. (ERIC Document Reproduction Service No. ED 451 157)

Chisholm, I. M. (1994). Preparing teachers for multicultural classrooms. The Journal of Educational Issues of Language Minority Students, 14, 43-68.

Clark, E. R., \& Flores, B. B. (2001).Who am I? The social construction of ethnic identity and self-perceptions of Latino preservice teachers. Urban Review, 33(2), 69-86.

Cuéllar, I., Arnold, B. \& Maldonado, R. (1995). The acculturation rating scale for Mexican Americans-II: A revision of the original ARSMA scale. Hispanic Journal of Behavioral Sciences, 17(3), 275-304.

Cuéllar, I., Nyberg, B., Maldonado, R. E., \& Roberts, R. E. (1997). Ethnic identity and acculturation in a young adult Mexican-origin population. Journal of Community Psychology, 25, 535-549.

Cummins, J. (2000). Language, power, and pedagogy: Bilingual children in the crossfire. Clevedon, England: Multilingual Matters.

de Mesquita, P. B., \& Drake, J. (1994). Educational reforms and the self-efficacy beliefs of teachers implementing nongraded primary school programs. Teaching and Teacher Education, 10(3), 291-302.

Dellinger, A. B., Bobbett, J. J., Olivier, D. F., \& Ellett, C. D. (2008). Measuring teachers' self-efficacy beliefs: Development and use of the TEBS-Self. Teaching and Teacher Education, 24(8), 751-766.

Espinosa, L. M. (1995). Hispanic parent involvement in early childhood programs. (ERIC Document Reproduction Service No. ED 382 412)

Flores, B. (2001). Bilingual education teachers' beliefs and their relation to self-reported practices. Bilingual Research Journal, 25, 275-299. 
Flores, B. B., Clark, E. R., Guerra, N.S., Sánchez, S. V. (2008). Acculturation among Latino bilingual education teacher candidates: Implications for teacher preparation institutions. Journal of Latino and Education, 7(4), 288-304.

Flores, B., \& Clark, E. R. (2004). A critical examination of normalistas' self-conceptualization and teacher-efficacy. Hispanic Journal of Behavioral Sciences, 26, 230-257.

Flores, B., Desjean-Perrotta, B., \& Steinmetz, L. E. (2004). Teacher efficacy: A comparative study of university certified and alternatively certified teachers. Action in Teacher Education, XXVI(2), 37-46.

Flores, B., Strecker, S., \& Pérez, B. P. (2002). Critical need for bilingual education teachers: The potentiality of normalistas and paraprofessionals. Bilingual Research Journal, 26(3), 687-708.

Flores, L. Y., Ojeda, L., Huang, Y.-P., Gee, D., \& Lee, S. (2006). The relation of acculturation, problem-solving appraisal, and career decision-making self-efficacy to Mexican American high school students' educational goals. Journal of Counseling Psychology, 53, 260-266.

Friedman, I. A., \& Farber, B. A. (1992). Professional self-concept as a predictor of teacher burnout. Journal of Educational Research, 86, 28-35.

Galguera, T. (1998). Students' attitude toward teachers' ethnicity, bilinguality, and gender. Hispanic Journal of Behavioral Sciences, 20(4), 411-428.

Genesee, F. (Ed). (1999). Program alternatives for linguistically diverse students (Educational Practice Report 1). Santa Cruz, CA: Center for Research on Education, Diversity and Excellence.

Ghaith, G. \& Yaghi, H. (1997). Relationships among experience, teacher efficacy, and attitudes toward the implementation of instructional innovation. Teaching and Teacher Education, 13, 451-458.

Gibson, S., \& Dembo, M. (1984). Teacher efficacy: A construct validation. Journal of Educational Psychology, 76, 569-582.

Giles, H., Coupland, N. Williams, A., \& Leets, L. (1991). Integrating theory in the study of minority languages. In R. L. Cooper \& B. Spolsky (Eds.), The influence of language on culture and thought: Essays in honor of Joshua A. Fishman's sixty-fifth birthday (pp. 113-136). New York: Mouton de Gruyter.

Goddard, R. D., Hoy, W. K., \& Hoy, A. W. (2000). Collective teacher efficacy: Its meaning, measure, and impact on student achievement. American Educational Research Journal, 37(2), 479-507.

Goddard, R. D., Tschannen-Moran, M., \& Hoy, W, K. (2001). Teacher trust in students and parents: A multilevel examination of the distribution and effects of teacher trust in urban elementary schools. Elementary School Journal, 102, 3-17.

Hoy, W. K., \& Woolfolk, A. E. (1993). Teachers' sense of efficacy and the organizational health of schools. The Elementary School Journal, 93(4), 355-372.

Houston, W. R., Marshall, F., \& McDavid, T. (1993). Problems of traditionally prepared and alternatively certified first-year teachers. Education and Urban Society, 26(1), 78-89.

Jerald, C. D. (2007). Believing and achieving. Washington, DC: Center for Comprehensive School Reform and Improvement.

Karabenick, S. A., \& Clemens Noda, P. A. (2004). Professional development implications of teachers' beliefs and attitudes toward English language learners. Bilingual Research Journal, 28(1), 55-75.

Marzano, R. J., Marzano, J. S., \& Pickering, D. J. (2003). Classroom management that works: Research-based strategies for every teacher. Alexandria, VA: Association for Supervision and Curriculum Development.

Meier, K., Wrinkle, R.D., \& Polinar, J. L. (1999).Representative bureaucracy and distributional equity: Addressing the hard question. Journal of Politics, 61(4), 1025-1039.

Menken, K. (2008). English learners left behind: Standardized testing as language policy. Clevedon, England: Multilingual Matters.

Monsivais, G. I. (1990). Latino teachers: Well educated but not prepared (An executive summary). Tomas Rivera Center, Claremont, CA. (ERIC Document Reproduction Service No. ED 372 887)

National Center for Education Statistics. (2008). School and Staffing Survey. Retrieved March 19, 2009 from http://nces.ed.gov/surveys/sass/tables.asp

No Child Left Behind Act of 2001, Pub. L. 107-110 (2002). Retrieved July 18, 2006, from http://www.ed.gov/policy/elsec/leg/esea02/index.html 
Ogbu, J. U. (1995). Understanding cultural diversity and learning. In J. A. Banks \& C.A.M. Banks (Eds.), Handbook of Research on Multicultural Education (pp. 582-593). New York: Macmillan.

Peña, R. A. (1997). Cultural differences and the construction of meaning: Implications for the leadership and organizational context of schools. Education Policy Analysis Archives, 5(10). Retrieved June 26, 2009, from http://epaa.asu.edu/epaa/v5n10.html

Phinney, J. (1992). The Multigroup Ethnic Identity Measure: A new scale for use with adolescents and young adults from diverse groups. Journal of Adolescent Research, 7, 156-176.

Phinney, J. (1996). Understanding ethnic diversity. American Behavioral Scientist, 40, 143-152.

Phinney, J. S. (2003). Ethnic identity and acculturation. In K. Chun, P. Organista, \& G. Marin (Eds.), Acculturation: Advances in theory, measurement, and applied research (pp. 63-81). Washington, DC: American Psychological Association.

Phinney, J. S., Chavira,V., \& Tate, J.D. (1993). The effect of ethnic threat on ethnic self-concept and own-group rating. Journal of Social Psychology, 133(4), 469-479.

Phinney, J., \& Ong, A. (2007). Conceptualization and measurement of ethnic identity: Current status and future directions. Journal of Counseling Psychology, 54(3), 271-281.

Sheets, R. H. (1996). Urban classroom conflict: Student teacher perception: Ethnic integrity, solidarity, and resistance. Urban Review, 28, 165-183.

Tong, F. (2009). In-service bilingual/ESL teachers' teaching efficacy, attitudes toward native language instruction and perception on English language learners: What do we know from the field? TABE Journal, 11(1), 1-33.

Tournaki, N., Lyublinskaya, I., \& Carolan, B. V. (2009). Pathways to teacher certification: Does it really matter when it comes to efficacy and effectiveness? Action in Teacher Education, 30, 96-109.

Trueba, H. T. (2002). Multiple, ethnic, racial, and cultural identities in action: From marginality to a new cultural capital in modern society. Journal of Latinos and Education, 1(1), 7-28.

Tschannen-Moran, M., \& Woolfolk-Hoy, A. (2001). Teacher efficacy: Capturing an elusive construct. Teaching and Teacher Education, 17, 783-805.

Villegas, A. M., \& Lucas, T. (2002). Preparing culturally responsive teachers: Rethinking the curriculum. Journal of Teacher Education, 33(1), 20-32.

Wang, M. C., Haertel, G. D., \& Walberg, H. J. (1993). Toward a knowledge base for school learning. Review of Educational Research, 63(3), 249-294.

Ware, H., \& Kitsantas, A. (2007). Teacher and collective efficacy beliefs as predictors of professional commitment. The Journal of Educational Research, 303-310.

Wayman, J., Foster, A., Mantle-Bromley, C., \& Wilson, C. (2003). A comparison of the professional concerns of traditionally prepared and alternative licensed new teachers. The High School Journal, 86(3), 35-40.

Wren, D. J. (1999). School culture: Exploring the hidden curriculum. Adolescence, 34, 593-596.

Zirkel, S. (2002). Is there a place for me? Role models and academic identity among white students and students of color. Teacher College Record, 104(2), 357-375.

Table 1. Breakdowns of teacher demographic background by type of program served

\begin{tabular}{llllcll}
\hline & \multicolumn{2}{c}{ Overall } & \multicolumn{2}{c}{ ESL (n=12) } & \multicolumn{2}{c}{ Bilingual (n=76) } \\
& & $\mathrm{n}$ & $\mathrm{n}$ & $\mathrm{n}$ & $\mathrm{n}$ & $\%$ \\
\hline \multirow{3}{*}{ Years of Teaching } & 1-less than 5 years & 14 & 1 & 8 & 13 & 17 \\
& 5-10 years & 35 & 7 & 58 & 28 & 37 \\
& 11-20 years & 31 & 4 & 33 & 26 & 34 \\
Route to & $>21$ years & 8 & & & 7 & 9 \\
Certification & University-based & 41 & 8 & 67 & 21 & 28 \\
& Alternative & 48 & 4 & 33 & 54 & 71 \\
Degree Held & Bachelor & 74 & 10 & 83 & 63 & 83 \\
& Master & 14 & 2 & 17 & 11 & 14 \\
& Doctorate & 2 & & & 2 & 3 \\
\hline
\end{tabular}

Notes. One respondent did not provide information on program served; two did not provide information on years of teaching; one did not provide information on route to certification. 


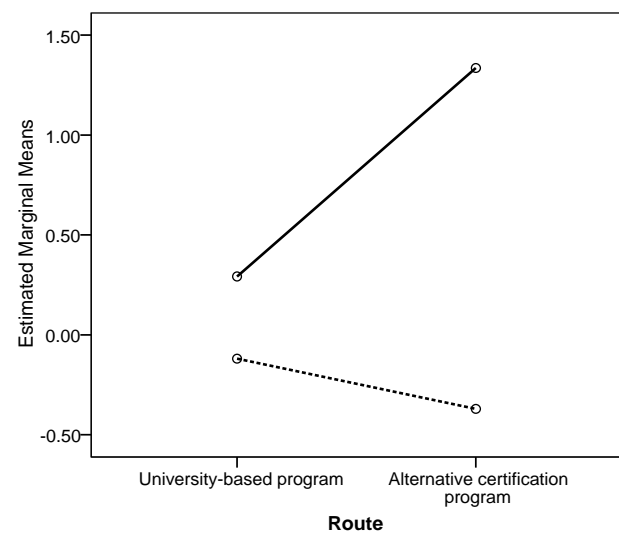

Program

- ESL

-...- Bilingual

Figure 1. Acculturation by Route to Certification and Program

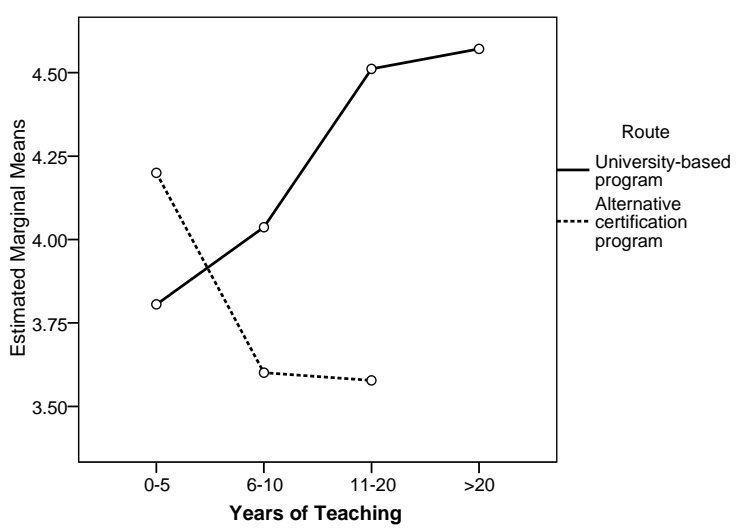

Figure 2. Ethnic Identity by Years of Teaching and Route to Certification

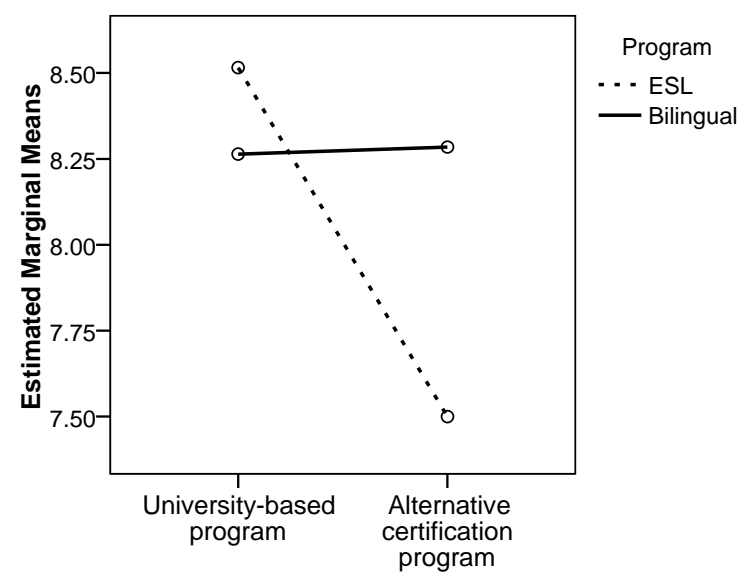

Route

Figure 3. Efficacy on Classroom Management by Program and Route to Certification 